\title{
PENGGUNAAN METODE REBA UNTUK MENGETAHUI KELUHAN MUSCULOSKELETAL DISORDER PADA PEKERJA SEKTOR INFORMAL
}

\author{
Madschen Sia Mei Ol Siska Selvija Tambun \\ Jurusan Teknik Industri, Fakultas Sains dan Teknologi, Universitas Sari Mulia \\ Jalan Pramuka No.2, Banjarmasin, Kalimantan Selatan \\ Email : marunehutabarat10041979@gmail.com
}

\begin{abstract}
Abstrak-Pekerja sektor informal merupakan sektor pekerjaan yang mendukung terlaksananya pembangunan di Indonesia terutama dalam menghadapi revolusi 4.0. Akan tetapi, jika ditinjau dari aspek $\mathrm{K3}$, sektor informal kurang mendapat perhatian. Salah satunya adalah dari aspek ergonomic. Dalam penilaian tingkat pekerjaan dari aspek ergonomi, banyak peneliti menggunakan metode REBA. Metode REBA bertujuan untuk menilai tingkat resiko ergonomi bagian tubuh atas dan bawah. Dalam jurnal penelitian ini dilakukan kajian singkat metode REBA yang digunakan pada pekerja pemecah batu, penjemuran kerupuk dan pemecah abut akik. Ketiga jurnal penelitian ini didukung oleh penelitian dengan responden pekerja tas Kendal.
\end{abstract}

Kata Kunci : REBA, Ergonomi, Pekerja Sektor Informal dan Tingkat Resiko Ergonomi.

\section{PENDAHULUAN}

Indonesia dalam menghadapi revolusi 4.0 mendapat dukungan dari berbagai sektor pekerja termasuk dari sektor informal. Pekerjaan baik untuk sektor formal dan informal cenderung mengalami perubahan dalam beberapa tahun terakhir ini. Seperti data yang dirilis oleh Badan Pusat Statistik (BPS) pada tahun 2018, bahwa penduduk Indonesia yang bekerja pada sektor informal sebanyak 73,98 juta orang $(58,22$ persen) [1].

Setiap jenis dan tempat pekerjaan baik pada pekerja formal maupun informal memiliki risiko yang dapat menyebabkan gangguan kesehatan. Pada umumnya para pekerja sektor informal kurang memiliki kesadaran dan pengetahuan tentang bahaya di lingkungan kerjanya [2]. Selain masalah gizi, penyakit tidak menular, dan penyakit menular, para pekerja informal juga memiliki risiko keselamatan dan kesehatan terkait pekerjaannya yang dapat mengganggu produktifitas mereka seperti kondisi lingkungan kerja yang berbahaya, masalah kesehatan seperti gangguan otot rangka, gangguan mata dan gangguan kesehatan kulit. Para pekerja informal terpapar potensi bahaya pekerjaan dengan kecenderungan tidak ada badan usaha ataupun pemilik yang secara langsung bertanggung jawab atas kesehatan dan keselamatan kerja mereka terutama yang berhubungan dengan berbagai penyakit dan gangguan akibat kesehatan dan kecelakaan kerja [2]. Salah satu aspek Keselamatan dan Kesehatan Kerja yang perlu diperhatikan adalah aspek risiko ergonomik yaitu Musculosceletal Disorder.

Keluhan Musculoskeletal adalah keluhan pada bagianbagian otot skeletal yang dirasakan oleh seseorang mulai dari keluhan yang sangat ringan sampai berat. Jika dalam hal ini otot menerima beban statis secara berulang dan dalam waktu yang lama maka dapat menyebabkan kerusakan pada otot, saraf, tendon, persendian, kartilago dan discus invertebrata [3].

Dalam menentukan terdapat keluhan musculoskeletal untuk seluruh bagian tubuh pada pekerja, peneliti ergonomic sering memakai metode Rapid Entire Body Assessment (REBA). Rapid Entire Body Assessment (REBA) dikembangkan untuk mengkaji postur bekerja yang ditemukan pada industry pelayanan kesehatan dan industry pelayanan lainnya. Data yang dikumpulkan berupa postur tubuh , besarnya gaya/beban yang digunakan, tipe dari pergerakan, gerakan berulang dan pegangan. Hasil akhir dari skor REBA dapat menunjukkan adanya sebuah indikasi dari tingkat risiko dan pada bagian mana yang harus dilakukan tindakan penanggulangan. Metode REBA ini diusulkan untuk menilai postur tubuh yang berisiko dengan work related musculoskeletal disorders (WRMSDs) [4].

REBA didesain untuk digunakan sebagai alat pengontrol keadaan berdasarkan pengumpulan data yang kompleks. Namun baru-baru ini telah dikomputerisasi oleh Janek et.al sehingga memudahkan bagi pengguna. Perkembangan awal metode ini didasari oleh range dari posisi anggota badan menggunakan konsep dari RULA, OWAS dan NIOSH. Garis dasar dari tubuh adalah fungsi anatomi pada posisi netral [4].

\section{METODE PENELITIAN}

Adapun metode penelitian dilakukan dengan menelaah tiga jurnal penelitian yang dilakukan pada pekerja sektor informal. Telaah jurnal penelitian ergonomi pada jurnal nasional. Dapat dilihat pada tabel dibawah ini jurnal yang akan ditelaah :

\begin{tabular}{|c|c|c|}
\hline No. & $\begin{array}{c}\text { Judul artikel } \\
\text { ilmiah }\end{array}$ & Keterangan \\
\hline 1. & $\begin{array}{l}\text { Hubungan Tingkat } \\
\text { Risiko Ergonomi } \\
\text { Dan Masa Kerja } \\
\text { Dengan Keluhan } \\
\text { Musculoskeletal } \\
\text { Pada Pekerja } \\
\text { Pemecah Batu [5] }\end{array}$ & $\begin{array}{l}\text { JURNAL } \text { KESEHATAN } \\
\text { MASYARAKAT (e-journal), } \\
\text { Volume 2 Nomor 3, Maret } \\
2014 . \quad \text { Online } \\
\text { http://ejournal- } \\
\text { s1.undip.ac.id/index.php/jkm }\end{array}$ \\
\hline 2. & $\begin{array}{l}\text { Analisis Keluhan } \\
\text { Rasa Sakit Pekerja } \\
\text { Dengan } \\
\text { Menggunakan } \\
\text { Metode REBA Di }\end{array}$ & $\begin{array}{l}\text { e-jurnal Teknik Industri FT } \\
\text { USU Vol.5. No.1. Maret } 2014 \\
\text { pp. 26-30 ISSN 2443-0579 } \\
\text { online/ISSN 2443-0560 print }\end{array}$ \\
\hline
\end{tabular}




\begin{tabular}{|c|c|c|}
\hline & $\begin{array}{l}\text { Stasiun Penjemuran } \\
{[6]}\end{array}$ & \\
\hline 3. & $\begin{array}{lr}\text { Analisis } & \text { Postur } \\
\text { Kerja } & \text { Pekerja } \\
\text { Proses Pengesahan } \\
\text { Batu Akik Dengan } \\
\text { Menggunakan } \\
\text { Metode REBA [7] }\end{array}$ & $\begin{array}{l}\text { Jurnal Teknovasi Volume 03, } \\
\text { Nomor } 1,2016,16-25 \text { ISSN : } \\
2335-701 X\end{array}$ \\
\hline
\end{tabular}

\section{HASIL DAN PEMBAHASAN}

Dari penelusuran terhadap tiga jurnal penelitian seperti pada tabel diatas, ketiga jurnal tersebut menggunakan metode REBA untuk mengetahui tingkat risiko ergonomi pada masingmasing pekerja.

\begin{tabular}{|l|}
\hline Responden \\
\hline Pekerja pemecah batu dengan jumlah responden sebanyak 30 \\
orang \\
\hline Metode Penelitian Yang Digunakan \\
\hline Penelitian kuantitatif dengan menggunakan metode observasi \\
dan pendekatan cross sectional \\
\hline Proses Penelitian \\
Fokus dalam penelitian ini adalah besarnya tingkat risiko \\
ergonomi dari pekerjaan pemecah batu yang dapat \\
menyebabkan keluhan musculoskeletal. Pada saat melakukan \\
penelitian, tahap pertama yang dilakukan adalah dengan \\
observasi dan setelah itu dilakukan dengan proses perekaman \\
yang berguna untuk mendapatkan gambar dan mengetahui \\
banyaknya gerakan berulang yang dilakukan oleh pekerja. \\
Tahap kedua adalah dengan melakukan wawancara kepada \\
para pemecah batu untuk mengetahui karakteristik responden \\
dan keluhan musculoskeletal pekerja. Dan metode yang \\
digunakan untuk mengetahui tingkat risiko ergonomi adalah \\
dengan REBA. \\
\hline Hasil Penelitian \\
Hasil penelitian pada responden menunjukkan sebanyak 16 \\
orang (53\%) melakukan pekerjaan dengan tingkat risiko \\
rendah. Sedangkan responden yang melakukan pekerjaan \\
dengan tingkat risiko tinggi sebanyak 14 orang (46,7\%). \\
\hline
\end{tabular}

\begin{tabular}{|c|}
\hline Responden \\
\hline $\begin{array}{l}\begin{array}{l}\text { Pekerja Pembuat Kerupuk Pada } \\
\text { sebanyak } 2 \text { orang }\end{array} \\
\end{array}$ \\
\hline Metode Penelitian Yang Digunakan \\
\hline Metode Deskriptif \\
\hline Proses Penelitian \\
\hline $\begin{array}{l}\text { Penelitian diawali dengan peninjauan dan pengumpulan data } \\
\text { di lapangan. Pada saat obeservasi penelitian, postur pekerja } \\
\text { dilihat dengan menggunakan metode lembar kerja REBA. }\end{array}$ \\
\hline Hasil Penelitian \\
\hline $\begin{array}{l}\text { Pada penitian ini, terdapat } 9 \text { tahap kegiatan pada stasiun } \\
\text { penjemuran. Dimana untuk tingkat risiko ergonomi tinggi } \\
\text { sebanyak } 4 \text { kegiatan yaitu meletakkan kerupuk basah ke atas } \\
\text { sarang, mengangkat ebek, memindahkan ebek, mengangkat } \\
\text { kerupuk untuk dijemur. Untuk tingkat risiko ergonomi sedang } \\
\text { sebanyak } 5 \text { tahap kegiatan yaitu mengambil kerupuk basah } \\
\text { yang telah direbus dari ebek, membawa ke tempat jemuran, }\end{array}$ \\
\hline
\end{tabular}

meletakkan kerupuk di tempat penjemuran, mengangkat ebek ke stasiun pencetakan, meletakkan ebek di stasiun

\begin{tabular}{|c|}
\hline Responden \\
\hline Pekerja Pengasahan Batu Akik \\
\hline Metode Penelitian Yang Digunakan \\
\hline Dokumentasi, wawancara dan data postur kerja \\
\hline Proses Penelitian \\
\hline $\begin{array}{l}\text { Penelitian diawali dengan peninjauan dan pengumpulan data } \\
\text { di lapangan. Pada saat obeservasi penelitian, postur pekerja } \\
\text { dilihat dengan menggunakan metode lembar kerja REBA. }\end{array}$ \\
\hline Hasil Penelitian \\
\hline $\begin{array}{l}\text { Pencatatan dan pengumpulan data mengenai postur kerja tiap } \\
\text { kegiatan menggunakan foto pada pekerja. Untuk skor REBA } \\
\text { pada bagian tubuh A (punggung, leher, kaki) dengan skor } 6 \text {. } \\
\text { Untuk skor REBA pada bagian tubuh B (lengan atas, lengan } \\
\text { bawah, pergelangan tangan) dengan skor } 4 \text {. Sedangkan untuk } \\
\text { skor REBA C adalah } 7 \text {. }\end{array}$ \\
\hline
\end{tabular}

Dengan melihat tiga jurnal penelitian diatas, ketiganya memakai metode REBA untuk menghitung tingkat risiko ergonomi pada pekerja atau responden. Metode REBA yang digunakan dapat mempermudah peneliti sebagai langkah awal untuk menilai postur tubuh pekerja dan tenaga yang digunakan tipe dari pergerakan pekerja tersebut. Selain itu, metode REBA dapat memperhitungkan beban yang ditangani dalam suatu system kerja, couplingnya dan aktivitas yan dilakukan.

Metode ini relatif mudah digunakan karena untuk mengetahui seberapa besar sudut anggota tubuh pada saat melakukan aktivitas, cukup hanya melihat dari range sudut bukan dari suatu sudut yang spesifik. Dan pada akhirnya, nilai dari REBA dapat digunakan tindakan apa selanjutnya yang harus dilakukan untuk mengurangi tingkat risiko ergonomi pekerjaan [8].

REBA dikembangkan untuk mendeteksi postur kerja yang beresiko dan melakukan perbaikan sesegera mungkin dan tanpa membutuhkan piranti khusus [7]. Dalam penggunaan metode REBA untuk mendapatkan perhitungan yang akurat, peneliti mengumpulkan data mengenai postur pekerja tiap kegiatan dengan menggunakan video atau foto. Setelah dilakukan pengambilan video atau foto, maka peneliti menentukan sudut terhadap postur bekerja. Adapun bagian tubuh yang dilihat sudut posturnya meliputi badan, leher, kaki, lengan bagian atas, lengan bagian bawah dan pergelangan tangan. Langkah selanjutnya adalah dengan menentukan berat beban, pegangan dan aktivitas kerja. Dan terakhir adalah menghitung skor akhir dari pekerjaan responden.

Dari tiga jurnal penelitian diatas, tingkat risiko ergonomi dengan menggunakan REBA berada pada tingkat risiko tinggi yang artinya perlu adanya perbaikan dari postur tubuh dan juga dari peralatan pekerja yang digunakan.

Jika melihat dari salah satu jurnal penelitian yaitu pekerja pada stasiun penjemuran kerupuk, pada tahap analisis fasilitas kerja aktual, bahwa ukuran dari sarang dan kursi pekerja tidak sesuai dengan dimensi pekerja yang menyebabkan pekerja cenderung membungkuk.. Kursi aktual yang ada di stasiun penjemuran membuat posisi kaki pekerja tidak seimbang. Keadaan pekerja yang membungkuk dan kaki yang 
tidak seimbang menyebabkan timbulnya keluhan rasa sakit pada pekerja dan menimbulkan resiko pekerjaan yang tinggi dari penilaian postur kerja. Posisi cenderung membungkuk inilah yang akhirnya mempengaruhi tingkat skor REBA [6].

Risiko postur tubuh yang salah atau dapat disebut postur janggal dapat menyebabkan kelelahan dan ketidaknyamanan. Dilakukannya postur janggal pada jangka waktu panjang dapat menyebabkan cidera dan keluhan pada jaringan otot rangka maupun saraf tepi [7].

Pemakaian metode REBA seperti tiga jurnal, didukung juga oleh penelitian sejenis dimana salah satunya adalah penelitian yang dilaksanakan pada pekerja sentra industry tas Kendal [9]. Tingkat risiko ergonomic postur tubuh pekerja dinilai dengan metode REBA. Dan hasil yang didapatkan adalah bahwa penilaian postur bagian pola dan gudang menunjukkan hasil tingkat risiko tinggi yang artinya segera diperlukan tindakan perbaikan. Tingginya nilai akhir REBA pada pekerja karena posisi kerja statis, dimana pekerja bekerja dalam posisi duduk dalam jangka waktu yang lama tanpa menggunakan alas duduk, leher menunduk secara terus menerus untuk menjangkau objek, punggung membungkuk, pergelangan tangan yang menahan pola pada saat menggambar dan pergerakan tangan kanan yang melakukan gerakan pengguntingan. Postur janggal pada pekerja juga memberi kontribusi untuk penilaian skor akhir REBA. Postur janggal disebabkan pekerja mengangkat beban terlalu berat tanpa alat bantu.

Penggunaan metode REBA ini juga didukung oleh adanya perekaman video proses pekerjaan dan dokumentasi gambar yang sebaiknya dilakukan secara terpisah oleh dua orang. Pada saat melakukan Analisa terhadap proses pekerjaan untuk mendapatkan postur bekerja juga dilakukan secara terpisah dan sesudah selesai dilakukan, maka akan dilakukan penyatuan apakah penilaian skor REBA baik dari perekaman video atau gambar mendapatkan hasil yang tidak terlalu jauh berbeda. Hal ini diperlukan untuk memvalidasi hasil satu sama lain.

\section{KESIMPULAN}

Metode REBA sampai saat ini masih efektif dan banyak digunakan oleh peneliti pada bidang ergonomi. Karena metode REBA ini merupakan langkah awal untuk mendeteksi tingkat risiko ergonomic pada pekerja. Selain itu, metode REBA sangat mudah dilakukan tanpa bantuan dari piranti lunak. Nilai akhir pada skor REBA akan dapat memberi solusi apakah pekerja tersebut memerlukan tindakan perbaikan segera. Metode REBA dapat membantu peneliti jika mau melakukan penelitian selanjutnya apabila skor REBA dinyatakan tinggi.

\section{SARAN}

Dari penelitian diatas, perlu adanya penambahan jurnal penelitian lain yang mendukung. Tidak cukup hanya tiga jurnal penelitian sehingga jurnal ini dapat lebih valid. Selain itu, penambahan jurnal penelitian yang sama bukan hanya skala nasional tetapi juga internasional.

\section{DAFTAR PUSTAKA}

[1] Badan Pusat Statistik, 2018. Keadaan Ketenagaankerjaan Indonesia Februari 2018. Berita Resmi No. 42/05/Th. XXI, 07 Mei 2018.

[2] Kementerian Kesehatan, 2016. Hidupkan Pos UKK Agar Pekerja Sektor Informal Tersentuh Layanan Kesehatan Kerja. https://www.kemkes.go.id/article/view/16110900002/hidupkanpos-ukk-agar-pekerja-sektor-informal-tersentuh-layanankesehatan-kerja-.html (diakses 10 Januari 2020).

[3] Tarwaka, dkk. 2004. Ergonomi Untuk Kesehatan dan Keselamatan Kerja dan Produktivitas. Surakarta: UNIBA.

[4] S. Higgnet and L. Mcatamney, "Technical Note, Rapid Entire Body Assessment," Applied Ergonomics, vol. 31, pp. 201-205, 2000.

[5] Rivai, Wahid Thoyib, Ekawati dan Jayanti, Siswi. 2014. Hubungan Tingkat Risiko Ergonomi Dan Masa Kerja Dengan Keluhan Musculoskeletal Pada Pekerja Pemecah Batu. Jurnal Kesehatan Masyarakat (e-journal), Volume 2 Nomor 3, Maret 2014. Online di http://ejournal-s1.undip.ac.id/index.php/jkm (diakses 10 Januari 2020).

[6] Hasibuan, Michella, Anizar dan Arto, Sugih. 2014. e-jurnal Teknik Industri FT USU Vol.5. No.1. Maret 2014 pp. 26-30 ISSN 24430579 online/ISSN 2443-0560 print (diakses 15 Januari 2020).

[7] Sulaiman, Fahmi dan Sari, Yosi Purnama. 2016. Jurnal Teknovasi Volume 03, Nomor 1, 2016, 16-25 ISSN : 2335-701X (diakses 15 Januari 2020).

[8] Staton, Neville dan Hedge, Allan. 2005. Handbook of Human Factors and Ergonomics Metods. Prentice hall of International Series. New Jersey.

[9] Setiorini, Ayu dkk. 2017. Analisis Postur Kerja Dengan Metode REBA Dan Gambaran Keluhan Subjektif Musculoskeletal Disorders (MSDs) (Pada Pekerja Sentra Industri Tas Kendal Tahun 2017). Jurnal Kesehatan. ISSN 1979-761 (Print). ISSN 2620-7761 (Online). Edisi Khusus, No.1.Februari 2019 (diakses 17 Januari 2020). 